\title{
Oxidative Refining of Metallurgical Grade Silicon: Lab-Scale Measurements on the Overarching Refining Behavior of $\mathrm{Ca}$ and $\mathrm{Al}$
}

\author{
ERLEND L. BJØRNSTAD, IN-HO JUNG, MARIE-ALINE VAN ENDE, \\ and GABRIELLA TRANELL
}

\begin{abstract}
Oxidative ladle refining (OLR) is the most widely used refining process for removal of dissolved $\mathrm{Ca}$ and $\mathrm{Al}$ in the industrial production of metallurgical grade silicon (MG-Si). Refining occurs by purging the silicon alloy with an oxygen-air mixture at temperatures preferably between 1823 $\mathrm{K}$ and $1873 \mathrm{~K}$, forming a $\mathrm{SiO}_{2}-\mathrm{CaO}-\mathrm{Al}_{2} \mathrm{O}_{3}$ slag, which is then separated from the liquid alloy before casting. To meet higher quality demands and customer specifications, it is paramount to achieve greater process control of the industrial system, which requires a deeper understanding of the $\mathrm{Ca}$ and $\mathrm{Al}$ mass transfer kinetics, and the general refining behavior. In this work, laboratory-scale experiments have been performed, aiming to emulate the industrial process. Five different alloy compositions, with varying initial $\mathrm{Ca}$ and $\mathrm{Al}$ concentration, were refined over 11 experiments, with samples taken at $0,5,7,10$, and 15 minutes at $1873 \mathrm{~K}$. A FactSage-based model was used to explore the underlying thermodynamic system behavior. The results suggest that OLR of MG-Si occurs in three primary steps, initially by the formation of slag by surface oxidation and purge gas, through the depletion of dissolved $\mathrm{Ca}$ in the melt, and secondarily by the formation of silica. Towards the end of the refining process, a critical amount of slag has been formed by the previous steps such that a global equilibrium is attained between the $\mathrm{SiO}_{2}-\mathrm{CaO}-\mathrm{Al}_{2} \mathrm{O}_{3}$ slag and the silicon alloy.
\end{abstract}

https://doi.org/10.1007/s11663-022-02425-5

(C) The Author(s) 2022

\section{INTRODUCTION}

OXIDATIVE ladle refining (OLR) is the most widely used refining process in the industrial production of metallurgical grade silicon (MG-Si, $\geq 96$ wt pet $\mathrm{Si}^{[1]}$ ), used primarily to reduce and control the amount of $\mathrm{Ca}$ and $\mathrm{Al}$ in the alloy. Other impurities, such as Fe, are controlled by choice of raw materials or through subsequent hydrometallurgical treatments. Since MG-Si primarily sees use as a raw material or alloying agent in the production of other materials, like aluminum alloys, silicones, steels, and photovoltaics, improvements made to the MG-Si production process, like OLR, will therefore benefit a wide range of industries.

ERLEND L. BJØRNSTAD and GABRIELLA TRANELL are with the Department of Materials Science and Engineering, Norwegian University of Science and Technology, 7491 Trondheim, Norway. Contact e-mail: erlend.1.bjornstad@ntnu.no IN-HO JUNG and MARIE-ALINE VAN ENDE are with the Department of Materials Science and Engineering and Research Institute of Advanced Materials, Seoul National University, Seoul 08826, Republic of Korea. Manuscript submitted June 7, 2021; accepted December 27, 2021. Article published online February 10, 2022.
In OLR, the molten alloy is purged with an oxygen-air gas mixture from a bottom-mounted porous plug, at temperatures between $1773 \mathrm{~K}$ and $1973 \mathrm{~K}$. This occurs while the alloy is being tapped from the furnace, and may continue for some time after the ladle is full to reach a specific target composition. The refining effect comes from oxygen in the purge gas reacting with the alloy to form a slag, where slag and alloy are immiscible, allowing impurities to be removed with the slag.

An Ellingham diagram ${ }^{[2]}$ shows that $\mathrm{Ca}$ and $\mathrm{Al}$ have a greater oxygen affinity than $\mathrm{Si}$, with $\mathrm{Ca}$ having a greater affinity for oxygen than $\mathrm{Al}$, but due to its abundance, it is assumed that $\mathrm{Si}$ is the first element to react with oxygen in the gas to silica, through Reaction 1. Silica then subsequently reacts with the impurity elements, mainly the two primary slag-forming impurities $\mathrm{Ca}$ and Al, through Reactions 2 and 3 respectively. Here (El) denotes that $\mathrm{El}$ is in the liquid slag, and $\mathrm{El}$ that $\mathrm{El}$ is dissolved in liquid silicon.

1. $\mathrm{Si}(\mathrm{l})+\mathrm{O}_{2}(\mathrm{~g})=\left(\mathrm{SiO}_{2}\right)$

2. $2 \mathrm{Ca}+\left(\mathrm{SiO}_{2}\right)=2(\mathrm{CaO})+\mathrm{Si}(\mathrm{l})$

3. $4 \underline{\overline{\mathrm{Al}}}+3\left(\mathrm{SiO}_{2}\right)=2\left(\mathrm{Al}_{2} \mathrm{O}_{3}\right)+3 \mathrm{Si}(\mathrm{l})$

A more comprehensive description of the reaction mechanisms can be found in Bjørnstad and Tranell. ${ }^{[3]}$ 
Only the $\mathrm{SiO}_{2}-\mathrm{CaO}-\mathrm{Al}_{2} \mathrm{O}_{3}$ slag will be considered in this work. All other minor impurity elements are either too noble for oxidative refining, or are expected to only exist in trace amounts. To attain greater control over the OLR process, our current understanding of the $\mathrm{Ca}$ - and Al-refining kinetics must be expanded. Industrial measurement campaigns are possible, but they are expensive to perform, and results sensitive in nature.

Hence, this work aims to carry out laboratory-scale experiments, focusing on large-scale effects, as these determine the refining path. Identifying these large-scale effects are critical for further work on creating mass transfer models to explore the refining kinetics of OLR in detail. A general problem when investigating the mass transfer between dissolved $\mathrm{Al}$ and $\mathrm{Ca}$ in $\mathrm{Si}$ and $\mathrm{SiO}_{2}-\mathrm{CaO}-\mathrm{Al}_{2} \mathrm{O}_{3}$ slags is that the mass transfers of $\mathrm{Al}$ and $\mathrm{Ca}$ are highly dependent on each other, ${ }^{[4]}$ making it difficult to separate out the refining effects themselves, but if said effects were known, they could more easily be accounted for in the future. The work follows from previous work by Kero et al., ${ }^{[5]}$ Haaland et al., ${ }^{[6]}$ and Olsen et al., ${ }^{[7]}$ who have all explored aspects of the OLR process.

\section{EXPERIMENTAL WORK}

To investigate the large-scale refining behaviors in $\mathrm{Si}$-alloys, with respect to $\mathrm{Ca}$ and $\mathrm{Al}$, a $2^{2}$ factorial design with a full replicate set and three center-points was selected as the overarching experimental design, seen in Table I. 0.5 and $1.5 \mathrm{wt}$ pct were chosen as extremes for both $\mathrm{Ca}$ and $\mathrm{Al}$, spanning the initial compositions relevant for the majority of alloys refined to MG-Si. An effort was made to attain a bubble flow regime similar to the general industrial case presented in Olsen et al. ${ }^{[7]}$ based on geometric and flow relations from Grace. ${ }^{[8]}$

\section{A. Materials and Experimental Setup}

Table II lists the raw materials and alloying materials used.

The refining experiments were conducted in an induction furnace, with a graphite crucible acting as the heat source, where Figure 1 provides a schematic representation of the whole setup.

A quartz crucible $(\varnothing 105 / 100 \times 380 / 375 \mathrm{~mm})$ separated the graphite and liquid alloy/purge gas, to ensure that the purge gas interacted primarily with the alloy. In six of the experiments, a quartz tube with the same dimensions was used instead, as it was found that the quartz crucible floor could be replaced by a $1 \mathrm{~cm}$ layer of a mullite-based refractory low-cement.

A lid was placed on top of the furnace, holding the top-mounted SiC lance. To reduce the effect of atmospheric oxygen, an argon gas shield was mounted inside the lid body. The shield consisted of a ring with 16 nozzles pointing towards the melt, delivering $4 \mathrm{NL} / \mathrm{min}$ of Ar 5.0 during the whole experiment. Different lance materials were tested, but only $\mathrm{SiC}$ tubes produced for use in high-temperature systems had the combination of low deterioration rate ${ }^{[10]}$ adequate mechanical strength at high temperatures, and thermal shock resistance required in this setup. The lance was heated along with the charge within a graphite sheath, which was removed before the purge gas was initiated.

Temperature was measured by a c-type thermocouple placed inside of an alumina tube, further placed inside a $\mathrm{SiC}$ tube, with its top sealed with cement. Both shielding and thermocouple were used for a maximum of two experiments each. Alloy samples were extracted using quart tubes $(\varnothing 6 / 3 \times 330 \mathrm{~mm})$, applying suction to the end of the tube not in contact with the alloy.

\section{B. Experimental Procedure}

Before heating, the experimental setup was assembled as depicted in Figure 1, with the quartz crucible containing approximately $2 \mathrm{~kg}$ of silicon $(5 \mathrm{~N})$. The charge was then heated until $1753 \mathrm{~K}$ over 30 to 40 minutes, after which the alloying elements were added. Each experiment was calculated to contain a total of $3 \mathrm{~kg}$ liquid silicon alloy after alloying. It was critical to rapidly submerge the aluminum, which was achieved by wrapping the foil around the SiCa-alloy chunks. The alloying process itself took between 15 and 30 minutes, depending primarily on alloying amount.

After all of the alloying elements were dissolved, the temperature was increased to $1873 \mathrm{~K}$. At $1873 \mathrm{~K}$, initial metal samples were taken, the graphite sheath was removed, the purge gas was initiated at $2 \mathrm{NL} / \mathrm{min},{ }^{*}$ and

*NL reference at 1 bar and $298 \mathrm{~K}$.

the lance inserted into the molten alloy. As the lance was inserted into the melt it would start to bubble and fume with small molten droplets ejecting from the surface from time to time, reminiscent of an industrial ladle. Alloy samples were taken after $0,5,7,10$, and 15 minutes. The samples were then extracted from the quartz tubes and further crushed in a wolfram carbide puck mill. After crushing, 0.3 to $1 \mathrm{~g}$ was sent for analysis by inductively coupled plasma sector-field mass spectrometry (ICP-SFMS).

\section{THERMODYNAMICS}

\section{A. New Solute Diagram}

In this work, no combinations of parameters were found which could approximate measurement values using the regular FT-lite database, together with FactPS and FT-oxid in FactSage 7.3. ${ }^{[1]}$ Several other authors have had similar experiences, proposing that commercial databases do not accurately represent the activity coefficient of dissolved $\mathrm{Ca}$ in $\mathrm{Si}$ at high temperatures. $^{[12-14]}$ A custom database was therefore made, using the activity coefficient at infinite dilution for dissolved $\mathrm{Ca}$ in $\mathrm{Si}$ at $1873 \mathrm{~K}$ from Jakobsson and Tangstad,${ }^{[13]}$ which resolved the problem. Substituting the custom database for FT-lite, a new solution diagram 
Table I. Table Listing the Randomly Generated Experiment Order, and the Initial Target Wt Pct of Ca and Al in Each Experiment

\begin{tabular}{lccccccccrrr}
\hline Replicate & 1 & 1 & 1 & 2 & 2 & 1 & 2 & 1 & 2 & 2 \\
\hline [Wt Pct Ca] & 0.5 & 0.5 & 1 & 0.5 & 1 & 1.5 & 1.5 & 1.5 & 0.5 & 1.5 \\
[Wt Pct Al] & 0.5 & 1.5 & 1 & 1.5 & 1 & 0.5 & 0.5 & 1.5 & 0.5 & 1.5 & 1 \\
\hline
\end{tabular}

Table II. Raw Material and Alloying Materials Used in the Experiment

\begin{tabular}{lll}
\hline Material & \multicolumn{1}{c}{ Purity } & \multicolumn{1}{c}{ Notes } \\
\hline Silicon & $\geq 99.999 \mathrm{wt}$ pct $(5 \mathrm{~N})$ & solar grade silicon \\
SiCa-Alloy & 2.80 to $5.20 \mathrm{wt} \mathrm{pct} \mathrm{Ca}$ & produced as approx. $600 \mathrm{~g}$ ingots \\
& $\pm 0.073 \mathrm{wt} \mathrm{pct}$ & sample RSD with $n=3$ \\
Aluminum & $\geq 99.0 \mathrm{wt}$ pct $(2 \mathrm{~N})$ & food grade aluminum foil
\end{tabular}

The relative standard deviation (RSD) noted for the SiCa alloy came from three replicate meta samples, made by crushing $0.5 \mathrm{~g}$ from five different SiCa-ingots together, all of which had a similar target concentration.

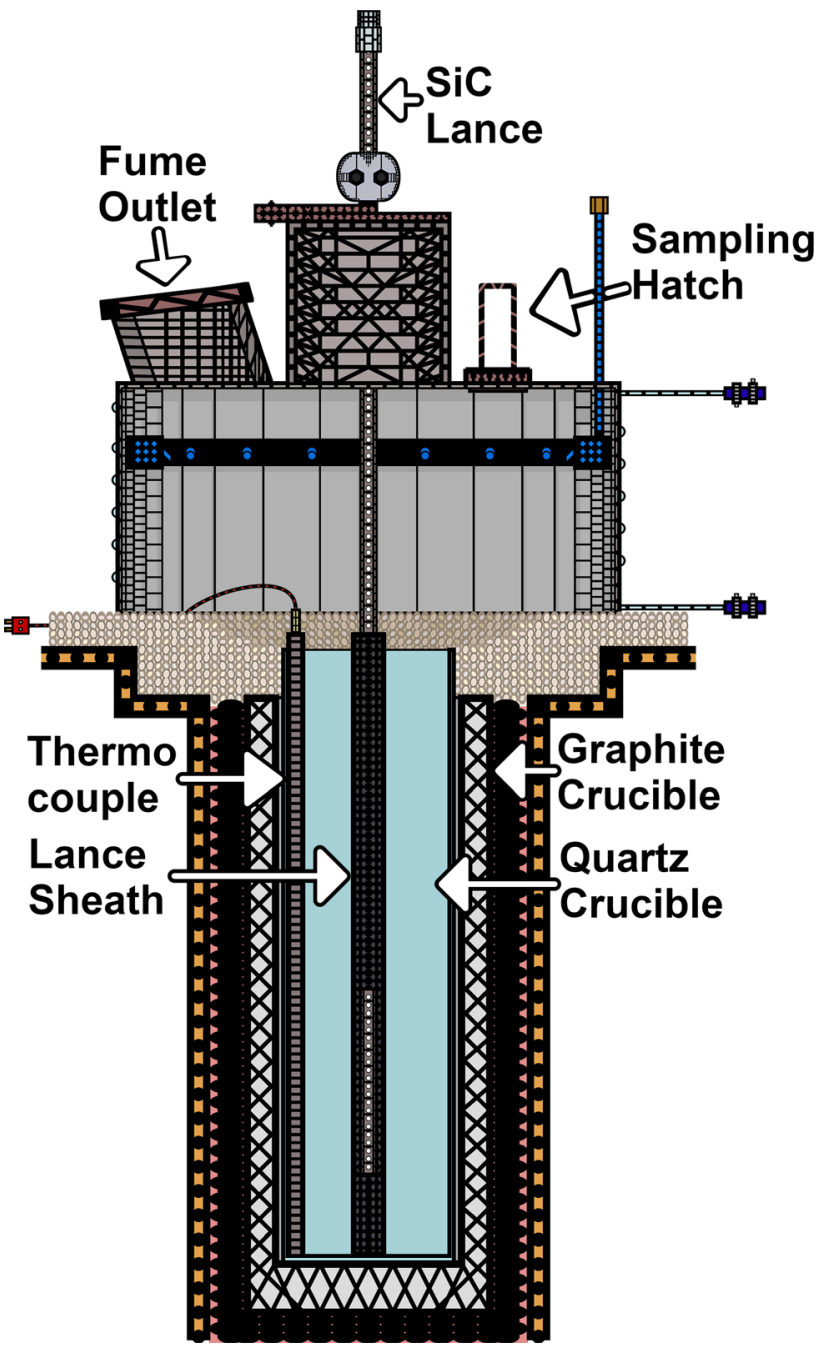

Fig. 1-Schematic representation of the relevant parts concerning the experimental setup, where an effort has been made to retain the relative scale between parts.

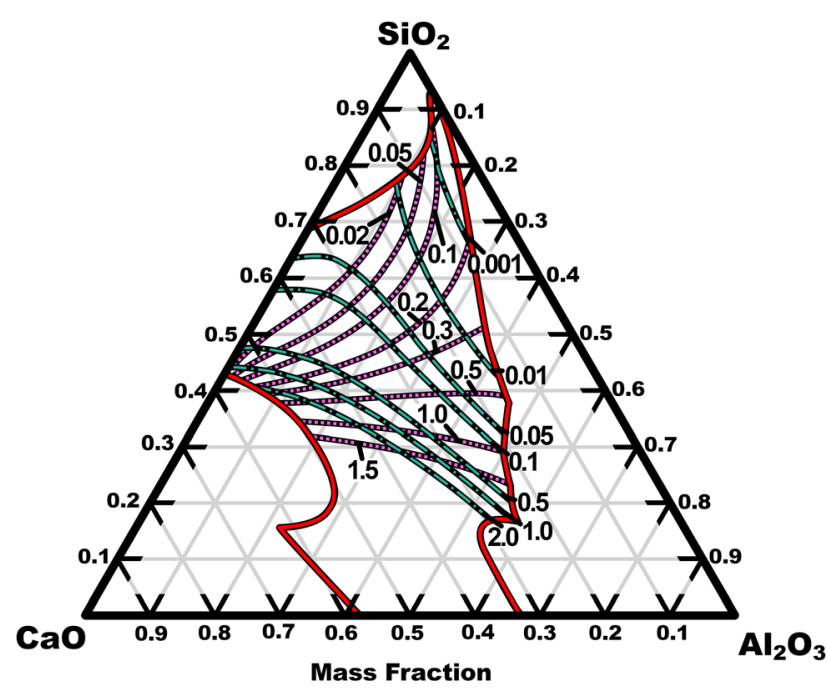

Fig. 2-Solution diagram for $\mathrm{Ca}$ and $\mathrm{Al}$ dissolved in $\mathrm{Si}(\mathrm{l})$ and in equilibrium with a liquid $\mathrm{SiO}_{2}-\mathrm{CaO}-\mathrm{Al}_{2} \mathrm{O}_{3}$ slag at $1873 \mathrm{~K}$. The dissolved equilibrium concentrations of $\mathrm{Ca}$ (blue line with dot) and $\mathrm{Al}$ (pink-stippled line) are in wt pet (Color figure online).

for $\mathrm{Ca}$ and $\mathrm{Al}$ dissolved in $\mathrm{Si}$ and in equilibrium with a $\mathrm{SiO}_{2}-\mathrm{CaO}-\mathrm{Al}_{2} \mathrm{O}_{3}$ slag at $1873 \mathrm{~K}$ was calculated using FactSage $7.3 .^{[11]}$ The new diagram can be seen in Figure 2 and is consistent with the work by Sigworth ${ }^{[12]}$ at $1823 \mathrm{~K}$.

\section{B. Thermodynamic Model}

Due to the selected experimental-design depth for breadth, the experimental work is less suited for kinetic modeling, as in Kero et al. ${ }^{[5]}$ and Olsen et al..$^{[7]}$ Thus, a thermodynamic model was constructed to explore how a simple melt/slag/gas system responds to different initial conditions, and indicate which conditions are necessary to attain specific refining effects. The model was run in 
FactSage $7.3^{[11]}$ in the Equilib module's macro processing environment using the FactPS, FT-oxid, and a custom database similar to FT-lite, described in Section III-A. Initial parameters were tuned by statistical model validation in MATLAB 2019b, through unconstrained non-linear regression by residual sum of square error minimization. The thermodynamic model used in this work considers three main processes occurring at each time step, which are:

(R1) Reaction between part of the Si-alloy and the gas bubbles, generating slag/oxide inclusions.

(R2) Reaction between part of the Si-alloy and the slag/inclusions.

(R3) Homogenization of the whole Si-alloy.

The primary assumptions made are that all of the slag/ inclusions are at equilibrium with each other and with part of the Si-alloy, all reactions are performed at equilibrium, all oxygen that is purged into the liquid alloy is consumed, all of the slag/inclusions remain in the liquid alloy, and that all three reactions occur within the same time step at every time step, an initial slag phase was also permitted. Amounts of $\mathrm{Ca}$ and $\mathrm{Al}$ in the $\mathrm{SiO}_{2}-\mathrm{CaO}-\mathrm{Al}_{2} \mathrm{O}_{3}$ slag are attained from the measurements, while the initial amount of silica in the slag was a tuning parameter. Other tuning parameters were volumetric gas flow rate, amounts of liquid metal which reacts the gas, and the fraction between the metal which reacts with the slag and the amount of slag. Temperature and gas composition were fixed at $1873 \mathrm{~K}$ and 21 pct $\mathrm{O}_{2}$, respectively.

\section{Predicted Refining Response}

The most important result from the modeling work was the importance of the oxygen source, originating from the purge gas or in the form of silica in the slag. In general, the purge gas introduces oxygen into the system by producing a silica-rich slag, where the silica is required to oxidize enough $\mathrm{Ca}$ and $\mathrm{Al}$ to allow the alloy to reach a global equilibrium with the slag currently in the crucible. If the amount of slag in the crucible is low, the amount of new slag produced by the purge gas will keep the alloy and existing slag from ever approaching equilibrium. This is due to the constant addition of new slag with a different composition changing the total slag composition significantly during each time step.

An example of this can be seen in Figure 3, where the mass of either alumina or calcia was set as an additional tuning parameter, with the other equal to its equilibrium amount. In both these cases, the initial amount of silica in the slag and volumetric gas flow rate are strongly negatively correlated, $q \approx-0.8, * *$ showing that they

\footnotetext{
**The correlation coefficient $q,(-1<q<1)$, where 0 is no correlation.
}

serve a similar purpose, but they are not entirely interchangeable. In Figure 3(a), the slag and alloy start close to their equilibrium, but as purging continues and more slag is formed, the slag and alloy drift farther apart from a global equilibrium. That $\mathrm{Ca}$ and $\mathrm{Al}$ are impacted differently is expected, and will be discussed at length in Section IV. Figure 3(b) shows a different case, where the slag and alloy are still drifting away from a global equilibrium, but in this case, the volumetric flow rate was tuned by the optimization algorithm to be close to 5 $\mathrm{NL} / \mathrm{min}$. This produced a large amount of slag, which is the reason why the alloy and slag compositions approach a global equilibrium towards the end.

If the initial slag phase is not forced to contain alumina and calcia, the optimization algorithm will often favor a slag phase consisting of high amounts of silica. Based on the performance of the optimization algorithm a specific refining behavior might not be possible for a given initial ratio of alumina and calcia, so when this ratio was added as a tuning parameter, it was often set by the algorithm to zero. This allows silica to react with $\mathrm{Ca}$ and $\mathrm{Al}$ as it pleases to attain a composition in global equilibrium with the melt. A global equilibrium reached this way is also very resilient, as the alloy has already been depleted of $\mathrm{Ca}$ and $\mathrm{Al}$ to form calcia and alumina by the silica present. As long as the amount of slag is not too low, initiating purging at this point will have little effect.

If the initial slag phase consisted purely of silica, then the optimization algorithm settled on parameters which stated that refining primarily occurred from the alloy moving towards a global equilibrium with the existing slag. In this case, the purge gas was not deemed necessary for refining and was relegated to only produce more silica, such that there were enough silica in the global slag phase to react with all of the $\mathrm{Ca}$ and Al. This can be seen in Figure 4.

\section{RESULTS AND DISCUSSION}

\section{A. Experimental Results}

As previously stated, the refining behaviors of $\mathrm{Ca}$ and Al are dependent of each other. To represent this dependency, the experimental measurements are plotted in Figure 5, which is part of the solute diagram from Figure 2, where $\mathrm{Ca}$ and $\mathrm{Al}$ dissolved in $\mathrm{Si}$ is in equilibrium with a $\mathrm{SiO}_{2}-\mathrm{CaO}-\mathrm{Al}_{2} \mathrm{O}_{3}$ slag. In the figure, each measurement set is color coded according to its experimental target initial concentration. There is a concentration disparity between the initial target and measured concentration, as seen in Figure 5 by the hexagons (measured initial composition) and squares (target initial composition) not overlapping.

The deviation is assumed to be the result of the alloy reacting with latent oxygen in atmospheric air, through the melt surface, during alloying and heating. A protective surface layer of silica will form, preventing further surface oxidation, where dissolved $\mathrm{Ca}$ and $\mathrm{Al}$ reacting with this layer as it forms. This surface layer also prevents any significant evaporation losses of $\mathrm{Ca}$ and A1. ${ }^{[15]}$ Calcia and alumina disrupt the pacifying silica layer, ${ }^{[3]}$ forming a less protective oxide layer which eventually becomes thick enough to pacify the melt 


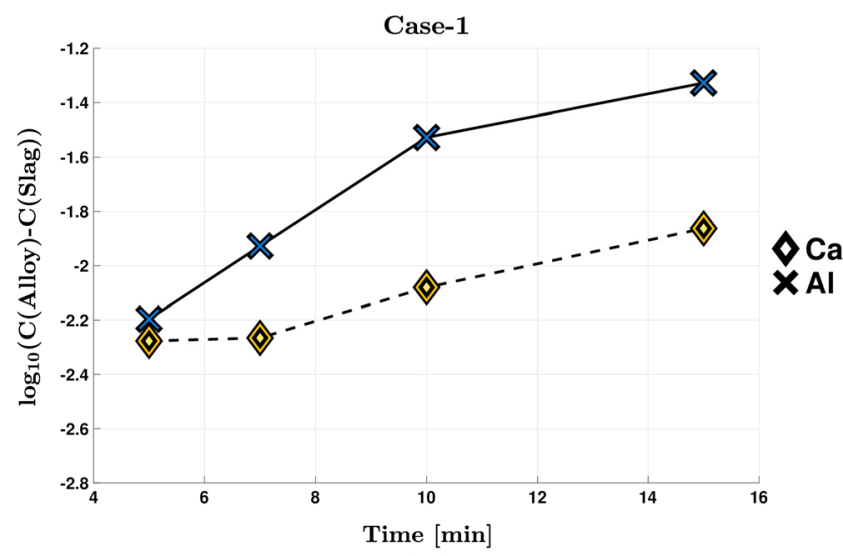

(a)

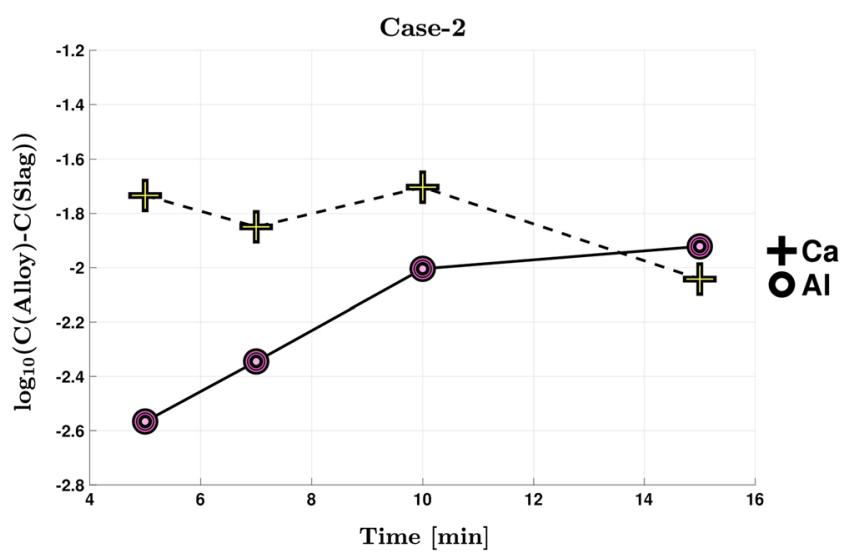

(b)

Fig. 3-Absolute difference between the calculated alloy composition and the alloy composition in equilibrium with the calculated slag composition at each time step. In (a), the amount of alumina in the initial slag was added as a tuning parameter, the concentration of calcia was set to the initial concentrations equilibrium value. In $(b)$, the amount of calcia was a tuning parameter, with the alumina concentration set to the equilibrium value.

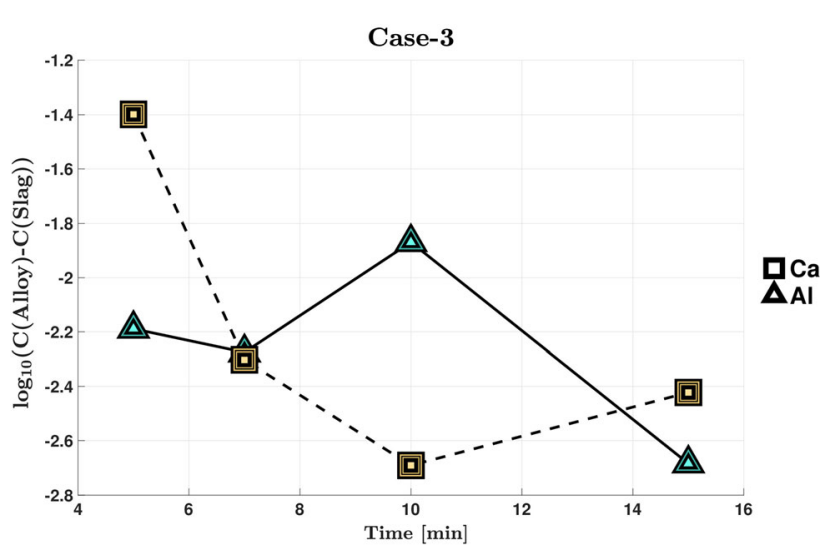

Fig. 4-Absolute difference between the calculated alloy composition and the alloy composition in equilibrium with the calculated slag composition at each time step. In this case, the initial slag phase consisted purely of silica $(22.65 \mathrm{~g})$.

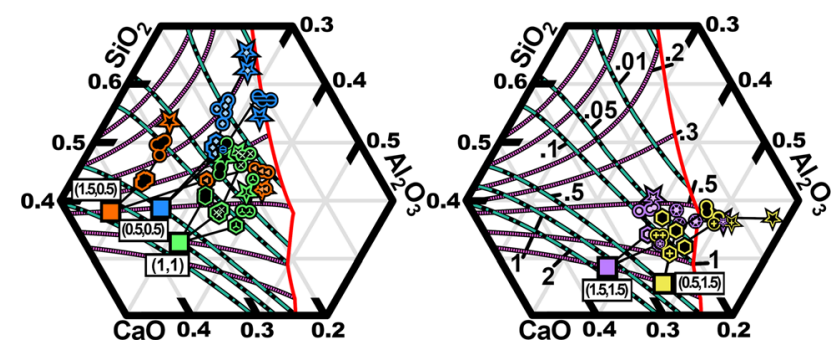

Fig. 5-Measured $\mathrm{Ca}$ (blue line with dot) and $\mathrm{Al}$ (pink-stippled line) concentrations plotted in segments from Fig. 2. Squares represent the target initial composition, with a tag specifying the composition. Hexagons and stars mark the measured initial and end concentrations, respectively. Every other sample during the refining cycle is marked with a circle (Color figure online).

surface. ${ }^{[15]}$ Thus, the higher amount of initial target impurities should necessitate a thicker surface layer, resulting in a greater pre-purging refining effect.

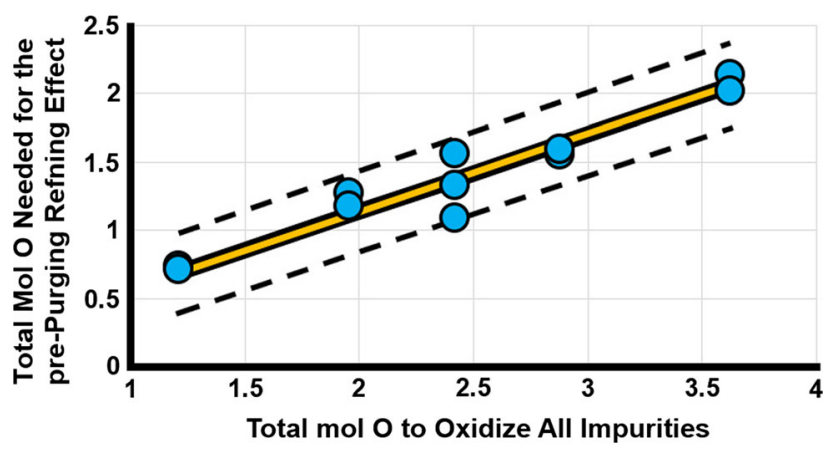

Fig. 6-Linear regression of the mean, with the estimated response $\hat{\mathrm{y}}=b_{1} \mathrm{x}$ as a full yellow line, where the fitted parameter $b_{1}=0.568$ has a 95 pct confidence interval of $[0.534,0.602]$. The regression 95 pct prediction interval is shown by stippled black lines, with inputs marked by blue dots. $t$-distribution is assumed (Color figure online).

This can be seen in Figure 6, where the total amount of oxygen needed to oxidize the difference in $\mathrm{Ca}$ and $\mathrm{Al}$ concentrations, between the initial target and measured compositions, expresses a significant linear behavior against the total amount of oxygen required to fully oxidize the target composition.

Describing the measurements in terms of their equilibrium $\mathrm{SiO}_{2}-\mathrm{CaO}-\mathrm{Al}_{2} \mathrm{O}_{3}$ slag, or "imaginary slag", in Figure 5 allows the refining path to be analyzed by the relative change in equilibrium slag composition between two points. How this imaginary equilibrium slag changes in composition will also reflect the compositional changes in the real slag, which are summarized in Table III. From data calculated from FactSage $7.3^{[11]}$ with FactPS, FT-oxid, and the custom database, the plotted iso-concentration lines of $\mathrm{Ca}$ and $\mathrm{Al}$ in Figure 5 reflect the iso-activity lines of calcia and alumina respectively, meaning no deviations due to slag activity must be separately accounted for. 
Table III. Relations Between an Imaginary Slag in Equilibrium With the Measurement Sets, and the Real Slag in the Crucible

\begin{tabular}{|c|c|c|c|c|c|}
\hline \multicolumn{3}{|c|}{ Imaginary Slag } & Real Slag & Notes & \\
\hline$\Delta(\mathrm{Wt}$ Pct $\mathrm{CaO})$ & $<$ & 0 & $\Delta m_{(\mathrm{CaO})}>0$ & & \\
\hline$\Delta\left(\right.$ Wt Pct $\left.\mathrm{Al}_{2} \mathrm{O}_{3}\right)$ & $\begin{array}{l}< \\
>\end{array}$ & $\begin{array}{l}0 \\
0\end{array}$ & $\Delta m_{\left(\mathrm{Al}_{2} \mathrm{O}_{3}\right)}>0$ & if [wt pct Al] & $\begin{array}{l}<1 \\
>1\end{array}$ \\
\hline$\Delta\left(\mathrm{Wt}\right.$ Pct $\left.\mathrm{SiO}_{2}\right)$ & $>$ & 0 & $\begin{array}{l}\Delta m_{\left(\mathrm{SiO}_{2}\right)}>0 \\
\Rightarrow m_{\text {Slag }}>0\end{array}$ & & \\
\hline
\end{tabular}

These relations are generated using a general mass balance on Figure 5, with the increase in amount of slag being due to reactions 3 and 2. Alumina is an amphoteric-oxide and thus changes its behavior depending on slag composition

Combining Figure 5 and Table III allows three primary refining regions to be determined. First, the line between the target and measured initial concentration, representing the pre-purging refining effect, shows the formation of a calcia-rich $\mathrm{SiO}_{2}-\mathrm{CaO}-\mathrm{Al}_{2} \mathrm{O}_{3}$ slag in all of the measurement sets, in accordance with conclusions drawn by Kero et al. ${ }^{[5]}$ After purging is initiated, most of the measurement sets change to favor producing a silica-rich $\mathrm{SiO}_{2}-\mathrm{CaO}-\mathrm{Al}_{2} \mathrm{O}_{3}$ slag, except for the measurement sets which meet the liquidus line between liquid slag/mullite, which start favoring an alumina-rich slag, likely indicating the formation of solid alumina-rich inclusions. All measurement sets which significantly change their refining behavior on interacting with the liquid slag/mullite line have an initial target concentration of $1.5 \mathrm{wt}$ pct $\mathrm{Al}$, with the two $(1.5,1.5)$ sets showing different behaviors, likely due to small compositional differences. This indicates that the formation of solid alumina-rich inclusions can be prevented with a sufficient amount of $\mathrm{Ca}$, but that it is very sensitive to $\mathrm{Ca}$ concentration. Towards the end, many of the sets deviate from their previous path to undergo compositional adjustments. These adjustments are suggested to represent the move towards a global equilibrium between the bulk slag accumulated in the crucible and the bulk alloy. A similar compositional behavior is observed during industrial refining, as described below, indicating the same underlying reaction mechanisms.

These adjustments may therefore be seen as the transition from refining by slag formation to refining by global slag equilibrium, where this transition is critical for industrial production, as any further changes to the alloy composition will require a change in the global slag composition, resulting in product losses (i.e., excess oxidation of the Si-alloy). That is, the problem becomes that the more slag is present in the ladle, the more slag must be generated to change its composition. To produce this slag, silica is needed, resulting in an exponentially cumulative loss of silicon to silica formation. Preferably, the desired slag composition is reached before the critical slag amount is attained, thus locking the desired composition in place. Reliable control over when this occurs is therefore paramount to improving process control. While not covered in this work, general industrial practice also indicates that changes in process temperature and additions of slag components will also impact the refining path and when the global equilibrium point is reached.

Each of the three refining stages described here has a different dominant refining effect with its own dominant oxygen source, aligning with the importance of said oxygen source found from the thermodynamic work. A summary of the refining progression described here is shown in Table IV.

\section{B. Industrial Comparison}

The measurements in this work were also compared with a large set of data from an industrial measurement campaign performed in 2016 on alloys with compositions similar to those in this work, supplied by one of Elkem's MG-Si plants, and can be seen in Figure 7. Here, each set has been normalized with respect to the ternary phase diagram, and each line-segment has been re-scaled to indicate what portion of the total refining time it represents. It must be noted that the figure represents the imaginary slag which is always in equilibrium with the alloy. Thus, a reduction of calcia in the imaginary slag represents an increase of calcia in the actual slag, resulting from the oxidation of dissolved $\mathrm{Ca}$ in the liquid Si-alloy, as in accordance with Table III. From the figure there are clear similarities between the lab-scale and industrial measurements initially, as they both exhibit the same behaviors of first producing a calcia-rich slag, then a silica-rich one.

As the industrial measurements show similar initial refining behavior to those at lab scale, it is possible to assume that industrial ladle refining also experiences surface oxidation. In the industrial case, when the liquid alloy is tapped into the ladle, the falling molten jet will first be scattered as it is deflected by the ladle floor, and later by impacting the liquid alloy surface as the ladle fills. The impinging jet flow caused by the jet impacting the ladle floor, creating ample opportunities for an exposed liquid alloy surface to come into contact with latent oxygen, from droplet formation during the fall and impact splashing, to wave formation and aeration. Purging at low fill heights additionally contributes to increase the contact area between the air and melt, where the falling jet and gas plume additionally break and emulsify the surface oxide layer, causing it to continuously reform. It might also explain why the industrial sets show an initial refining behavior leaning somewhat more towards alumina than that of silica in the lab-scale measurement sets, as the industrial case may experience more surface interaction.

Since the initial refining stage sees rapid depletion of $\mathrm{Ca}$, it might be more efficient to keep the initial gas purging to a minimum, and rather ramp it up when a greater melt volume is present in the ladle. If the concentration of $\mathrm{Ca}$ dips too low in the alloy, then the refining efficiency of other impurities goes down, like Al. Thus, it may be interesting to explore if Si-alloys with higher amounts of impurities like FeSi, which contains large amounts of $\mathrm{Al}$, can see higher refining efficiency if the initial purging is decreased. It may even be that surface oxidation is more preferable for certain alloys than 
Table IV. Description of the Refining Progression, Showing Which Refining Effect, Oxygen Source, and Formation of Which Slag Species Dominate the Refining Path of Al and Ca in MG-Si at a Given Refining Stage, Based on the Different Stages Seen in Fig. 5

\begin{tabular}{llll}
\hline Refining Stage & Pre-Purging & During Purging & End of Purging \\
\hline Refining Effect & surface oxidation & gas purging & slag equilibrium \\
Oxygen Source & latent oxygen & gas bubbles & bulk slag \\
Slag Species & $\mathrm{CaO}$ & $\mathrm{SiO}_{2}$ & $\mathrm{SiO}_{2} / \mathrm{CaO} / \mathrm{Al}_{2} \mathrm{O}_{3}$ \\
\hline
\end{tabular}

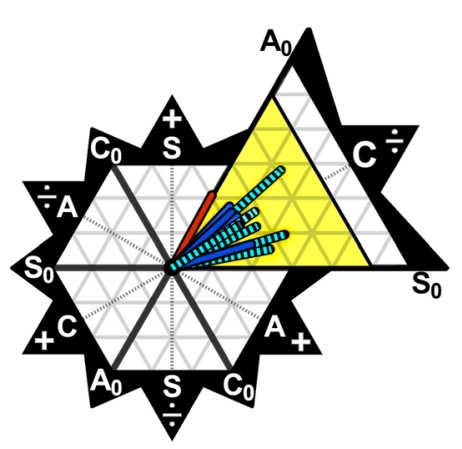

(a)

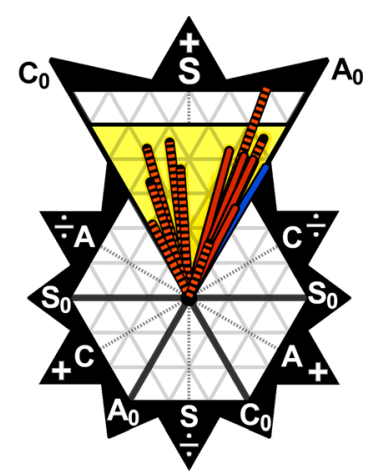

(b)
Fig. 7-Normalized ternary phase diagrams with respect to each sets initial equilibrium slag concentration. How these diagrams are constructed can be found in "Appendix 7." Industrial measurement sets are marked with stippled lines, while the measurements from this work are full lines. The sample sets with high initial $\mathrm{Al}$ concentration have been omitted. Lines in blue, red, and green line colors show the production of a calcia, silica, and alumina-rich slag, respectively, where the hexagonal section housing the most sets in each case is enlarged and given a yellow background. (a) shows the initial refining stage, while $(b)$ shows the second refining stage (Color figure online).

purging, as surface effects may allow the surface oxide layer to contain more of specifically undesirable impurities, allowing a targeted removal of these impurities.

\section{CONCLUSIONS}

- Lab-scale experiments simulating industrial OLR of MG-Si were performed.

- This was conducted by purging synthetic silicon alloys with synthetic air ( $2 \mathrm{NL} / \mathrm{min})$ for 15 minutes at 1873 $\mathrm{K}$, where the alloys differ with respect to their initial target $\mathrm{Ca}$ and $\mathrm{Al}$ content. A kinetic measurement series was performed for each alloy, sampling at 0,5 , 7,10 , and 15 minutes.

- The discrepancy between the initial target and measured compositions indicates that there was a consistent pre-purging refining effect. This effect was shown to be directly correlated with the target composition and was attributed to surface oxidation.

- Behavioral deviations were seen in three of the alloy samples with high initial target $\mathrm{Al}$ content. This was attributed to the formation of solid alumina-rich inclusions.

- A thermodynamic model was established to look at how a simple $\mathrm{Si}$-alloy- $\mathrm{SiO}_{2}-\mathrm{CaO}-\mathrm{Al}_{2} \mathrm{O}_{3}$ slag-gas system reacts to different initial conditions. The model showed that the oxygen source for slag production was critical.

- The overall refining behavior, which was also seen in the industrial measurements, and may be described as follows:

- Initially the refining occurs by the formation of a surface slag layer, controlled by the formation of calcia. If this surface slag layer is not disrupted then it will hinder any further surface oxidation.

- During gas purging, refining primarily occurs by slag formation on the gas bubbles, controlled by silica formation.

- Towards the end, enough slag has been formed such that a local slag equilibrium takes control of the refining behavior away from the gas bubbles. This is seen by the refining behavior suddenly shifting its refining path away from prioritizing silica formation, where the alloy is assumed to adjust its concentration to reach an equilibrium with the bulk slag.

\section{FUTURE WORK}

In on-going work, the reaction kinetics of $\mathrm{Si}, \mathrm{Ca}$, and $\mathrm{Al}$ reacting with oxygen to form $\mathrm{SiO}_{2}-\mathrm{CaO}-\mathrm{Al}_{2} \mathrm{O}_{3}$ slags is being investigated, with a focus on kinetic modeling. This would be aided greatly by performing experiments similar to those already performed in this work, focusing on fewer sample sets with higher sampling frequency to attain greater statistical depth rater than breadth. Further, it will also be interesting to investigate the pre-purging refining effect by performing a similar kinetic sampling series before initiating gas purging.

\section{ACKNOWLEDGMENTS}

This publication has been funded by the SFI Metal Production (Center for Research-Based Innovation, 237738). The authors gratefully acknowledge the financial support from the Research Council of Norway 
and the partners of the SFI Metal Production. We also wish to thank Elkem for allowing the use of their industrial data, and Trygve Storm Aarnæs at NTNU for his work on the furnace lid.

\section{CONFLICT OF INTEREST}

On behalf of all authors, the corresponding author states that there is no conflict of interest.

\section{FUNDING}

Open access funding provided by NTNU Norwegian University of Science and Technology (incl St. Olavs Hospital - Trondheim University Hospital).

\section{OPEN ACCESS}

This article is licensed under a Creative Commons Attribution 4.0 International License, which permits use, sharing, adaptation, distribution and reproduction in any medium or format, as long as you give appropriate credit to the original author(s) and the source, provide a link to the Creative Commons licence, and indicate if changes were made. The images or other third party material in this article are included in the article's Creative Commons licence, unless indicated otherwise in a credit line to the material. If material is not included in the article's Creative Commons licence and your intended use is not permitted by statutory regulation or exceeds the permitted use, you will need to obtain permission directly from the copyright holder. To view a copy of this licence, visit http://creat ivecommons.org/licenses/by/4.0/.

\section{APPENDIX: NORMALIZING VECTORS IN TERNARY SPACE}

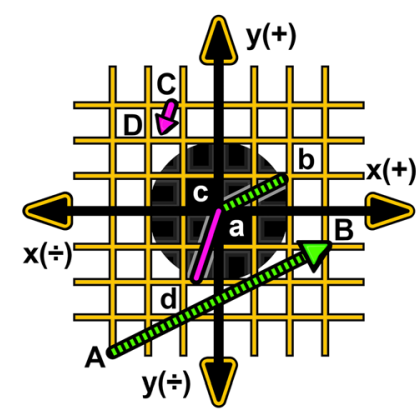

(a)

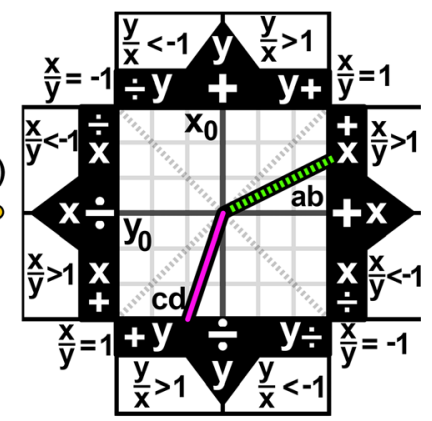

(b)
Fig. A1- (a) Cartesian coordination system (x, y), with the vectors $\mathrm{AB}$ and $\mathrm{CD}$ and their normalized counterparts $\mathrm{ab}$ and cd. The normalized vectors have been displaced such that they originate at the origin, with the black circle indicating the normalization length. (b) A diagram describing the relationship between a vector's $\mathrm{x}$ - and y-component, and their sign $(+, \div)$. It also contains the two normalized vectors $\underline{\mathrm{ab}}$ and $\underline{\mathrm{cd}}$ from (a).
A brief explanation of the normalizing schema used in the figures for representing lines in ternary space is explained below, where a more detailed explanation can be found in Reference 16.

In Cartesian space, here (x, y), any vector can be represented by two points in space, like the line between the points A and B in Figure A1(a), starting at point A. The vector $\mathrm{AB}$ has both direction and length, but if its direction is to be compared with $\mathrm{CD}$ their length can be normalized to 1 , and they can be displaced such that they originate at the origin (which crucially, is the coordinate systems center of mass). Since they all originate the same point, no arrow is needed to denote direction. Figure A1(a) shows this, where $\mathrm{ab}$ and $\mathrm{cd}$ are the normalized vectors of $\mathrm{AB}$ and $\mathrm{CD}$. The direction can be treated akin to a clock, which has a sign $(+, \div)$ and an angle, where the angle can be represented as a fraction between the vector's $\mathrm{x}$ - and y-component. To show what direction a combination of sign and angle will provide, a diagram like in Figure A1(b). Here, ab is shown to move in a direction positive to both $\mathrm{x}$ and $\mathrm{y}$, where $|x|>|y|$, while cd moves in a direction negative to $\mathrm{x}$ and $\mathrm{y}$, where $|\mathrm{y}|>|\bar{x}|$. This can also be though of as which component sees the largest change along any given direction, where the more change a component sees, the more dominant it is over the given direction. Showing the fractions is not very convenient, so the diagram indicates which vector component dominates the fraction by marking it on the border. The protruding arrow point indicates which component controls the given direction, which in ternary space will be different component than those taking part in the fraction. A vector component will always be at its most dominant the farther away the direction points from its iso-value line, denoted by $\mathrm{y}_{0}$ and $\mathrm{x}_{0}$ respectively, which is consequentially where it is at its weakest.

The ternary space used to create ternary phase diagrams is a plane in 3D Cartesian space $(x, y, z)$, bound by $1=\mathrm{x}+\mathrm{y}+\mathrm{z}$ and rotated such that the ternary center of mass, the $\left(\frac{1}{3}, \frac{1}{3}, \frac{1}{3}\right)$-point, and the ternary projection of the Cartesian center of mass, the origin, overlap. A metallurgical analogy to this, is why

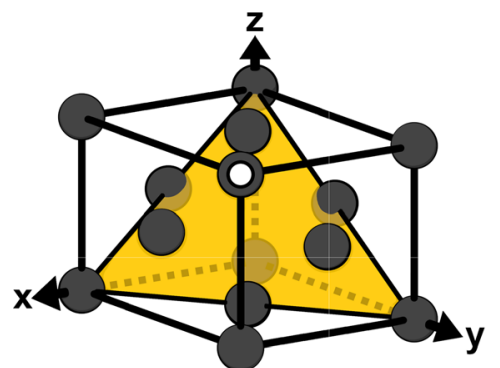

(a)

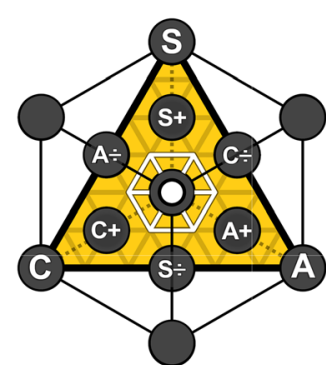

(b)
Fig. A2-(a) The FCC arrangement in a Cartesian coordinate system (x, y, z) with a bound plane similar to a ternary phase diagram. (b) (a) which has been rotated to align the centers of mass. Different points have been denoted to indicate the silica-calcia-alumina (SCA) phase diagram, and the compositional change that will occur for a given vector rooted at the center of mass. 


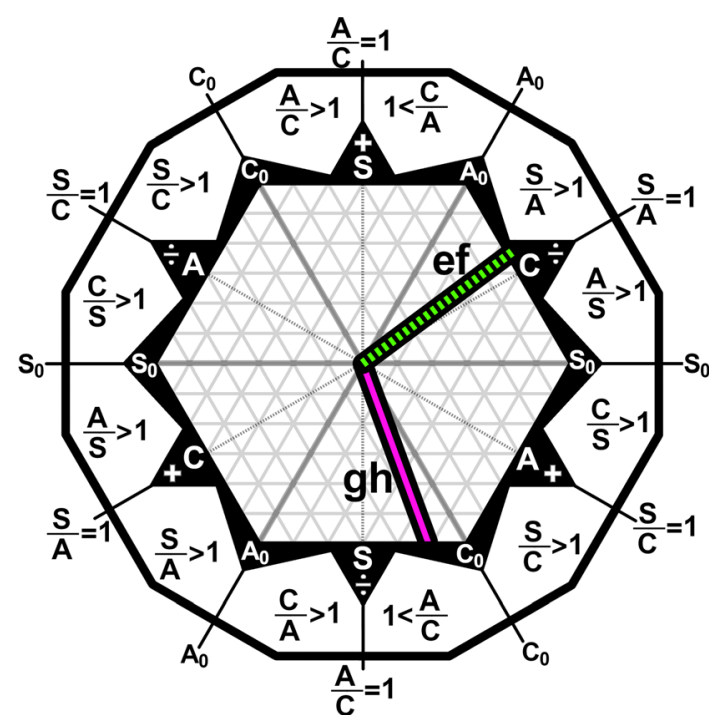

Fig. A3 - Ternary form of the diagram in Fig. A1(b), based on the relations in Fig. A2(b). The outer ring contains the fractional relations between the non-controlling species, displayed on a shorthand form on the inner hexagonal border. Protruding arrows on each hexagonal segment denotes the controlling species and its sign. $\mathrm{S}_{0}, \mathrm{C}_{0}$, and $\mathrm{A}_{0}$ denote the iso-concentration lines.

face centered cubic (FCC) is the cubic close packing (CCP) arrangement. One reason why FCC is close packing, is its ability to express hexagonal characteristics, establishing a connecting between it and the other close packing arrangement, hexagonal close packing (HCP). This hexagonal nature is also present in the ternary phase diagram, where two signs and three components in $2 \mathrm{D}$ space results in the unit hexagon shown in Figure A2. As in the 2D Cartesian case, there is nothing stopping one from normalizing and displacing a vector in ternary space, but as the center of mass has now shifted to the $\left(\frac{1}{3}, \frac{1}{3}, \frac{1}{3}\right)$-point, it will now instead serve as the new origin point for the normalized and displaced ternary vectors.

To simplify further discussions of the phase diagram the ternary vector components are set as the species SCA, as in Figure A2(b), representing the ternary silica-calcia-alumina phase diagram. In a ternary phase diagram, it can be shown that one species (and its sign) controls which section of the unit hexagon (white hexagon in Figure A2(b)) a vector points in, where a fraction between the two other species dictates what the specific angle is within said section. Thus, it can be stated that one of the species controls the overarching direction by specifying the section, while another dominates the fraction, thus influencing the direction in favor of changing the concentration of said dominating species. Figure A2(b) contains all the information needed to create a diagram like Figure A1(b), resulting in Figure A3.
In the example diagram Figure A3, the vector ef has a direction which is controlled by calcia, with a fraction slightly dominated by silica. Since the angle towards silica is not that much greater than alumina, it can be deduced that during ef it is primarily the calcia concentration which changes (decreases), where silica and alumina concentrations both increase by almost equal amounts. The vector gh on the other hand, describes a situation where silica controls the direction, and alumina strongly dominates the fraction. Here, the silica concentration will decrease, while the alumina concentration will increase much more than that of calcia. As with the Cartesian case, the further away a vector points from a species' iso-concentration line, the more that species' concentration will change compared to that of the others, shown here by gh almost pointing along calcia's iso-concentration line. Figure A3 can be used to compare any vector in a ternary phase diagram, like normal phase lines, iso-concentration lines of a species in solution, or iso-activity lines.

\section{REFERENCES}

1. M. Tangstad: in Ferrosilicon and Silicon Technology, Book Section from Handbook of Ferroalloys, M. Gasik, ed., $1^{\text {st }}$ ed., Elsevier Ltd., Amsterdam, 2013, pp. 179-83.

2. A. Schei, J. Kr Tuset, and H. Tveit: Production of High Silicon Alloys, $1^{\text {st }}$ ed., Tapir Forlag, Trondheim, 1998, p. 77.

3. E.L. Bjørnstad and G.M. Tranell: Metall. Mater. Trans. B, 2021, vol. 52B, pp. 1392-1412.

4. E.L. Bjørnstad and G.M. Tranell: Mater. Process. Fundam., 2017, vol. 2017, pp. 85-96.

5. I. Kero, M.K. Næss, V. Andersen, and G.M. Tranell: Metall. Mater. Trans. B, 2015, vol. 46B, pp. 1186-94.

6. D. Haaland, L.H. Lindstad, and J. Kr Tuset: Silicon for the Chemical Industry II, Tapir Forlag, Trondheim, 1994, pp. 271-82.

7. J.E. Olsen, D. Darmana, A. Ashrafian, and K. Tang: 6th Int. Conf. CFD Oil Gas Metall. Process Ind., Conf. Proc., Trondheim, Norway, 2008.

8. J.R. Grace: Trans. Inst. Chem. Eng., 1973, vol. 51, pp. 116-20.

9. EU standard EN 602:2004, $2^{\text {nd }}$ ed., Accessed 21 Sep 2020 from Standard Norge as Norwegian Standard NS-EN 602:2004.

10. N.S. Jacobson and R.A. Rapp: Tech. Mem. 106793, NASA, Ohio, 1995.

11. C.W. Bale, E. Bélisle, P. Chartrand, S.A. Decterov, G. Eriksson, A.E. Gheribi, K. Hack, I.-H. Jung, Y.-B. Kang, J. Melançon, A.D. Pelton, S. Petersen, C. Robelin, J. Sangster, P. Spencer, and M.-A. Van Ende: CALPHAD, 2016, vol. 55, pp. 1-19.

12. G.K. Sigworth: Can. Metall. Q., 2020, vol. 59, pp. 251-61.

13. L.K. Jakobsson and M. Tangstad: Metall. Mater. Trans. B, 2015, vol. 46B, pp. 596-605.

14. S.H. Ahn, L.K. Jakobsson, and G.M. Tranell: Metall. Mater. Trans. B, 2017, vol. 48B, pp. 308-16.

15. K. Hildal: Steam Explosions During Granulation of Si-Rich Alloy: Effect of Al- and Ca-additions, Ph.D. Thesis, IMA NTNU, Trondheim, 2002.

16. E.L. Bjørnstad: Oxidative Ladle Refining of Metallurgical Grade Silicon: Refining of $\mathrm{Ca}$ and $\mathrm{Al}$ Impurities, Ph.D. Thesis, IMA NTNU, Trondheim, 2021.

Publisher's Note Springer Nature remains neutral with regard to jurisdictional claims in published maps and institutional affiliations. 